\title{
PENDIDIKAN MULTIKULTURAL SEBAGAI UPAYA MENGHADAPI PERGESERAN BUDAYA DI ERA MILENIAL
}

\author{
Sesya Dias Mumpuni ${ }^{1}$, Laelia Nurpratiwiningsih ${ }^{2)}$ \\ ${ }^{1)}$ Program Studi Bimbingan dan Konseling, Universitas Pancasakti \\ ${ }^{2)}$ Program Studi Pendidikan Guru Sekolah Dasar, Universitas Muhadi Setiabudi \\ Email: ${ }^{1)}$ dias.mumpuni@live.com dan ${ }^{2)}$ laelia np89@gmail.com
}

\begin{abstract}
Abstrak
Tujuan dari penelitian ini untuk mengetahui sejauh mana efek perubahan budaya pada masyarakat pada era milenial. Manfaat yang dapat diambil dari penelitian ini adalah sebagai gambaran kesiapan masyarakat khususnya generasi muda yang sedang mengalami pergeseran budaya dari konvensional menuju era milenial berbasis aplikasi online. Metode yang digunakan adalah kualitatif studi kasus menggunakan pengumpulan data melalui observasi dan wawancara tertuju. Responden dalam penelitian ini adalah masyarakat di Kota Tegal yang dipilih dengan keriteria sebagai pengguna dan penyedia jasa dari aplikasi online. Hasil yang diperoleh dari penelelitian ini yaitu mengetahui pengguna, penyedia dan peruabahan budaya pada masyarakat ditinjau dari konseling lintas budaya. Dapat disimpulkan bahwa masyarakat di Kota Tegal sangat terbuka terhadap perubahan, dapat beradaptasi dengan globalisasi dan menjadi masyarakat yang sadar akan kebutuhan teknologi.
\end{abstract}

Kata Kunci: konseling lintas budaya, aplikasi online, globalisasi

\section{MULTICULTURAL EDUCATION AS AN EFFORT TO COPE WITH CULTURAL CHANGE IN THE MILLENIAL ERA}

\author{
Sesya Dias Mumpuni ${ }^{1)}$, Laelia Nurpratiwiningsih ${ }^{2)}$ \\ ${ }^{1)}$ Guidance and Counseling Program, Universitas Pancasakti \\ ${ }^{2)}$ Elementary School Teacher Program, Universitas Muhadi Setiabudi \\ Email: ${ }^{1)}$ dias.mumpuni@live.com dan ${ }^{2)}$ laelianp89@gmail.com
}

\begin{abstract}
The aim of this study to know the effect of cultural change on society in the millennial era. Benefits that can be taken from this research is as an illustration of the readiness of the people, especially the younger generation who are experiencing a change from conventional culture to the millenial era based on online applications. The method used is qualitative case study using data collection through observation and interviewed. Respondents in this study were people in Tegal City who were selected with keriteria as users and service providers of online applications. The results obtained from this research is to know the user, the provider and the culture of the society in terms of multicultural counseling. It can be concluded that the people in Tegal City are very open to change, can adapt to globalization and become a society that is aware of technology needs.
\end{abstract}

Keywords: multicultural counseling, online-based applications, globalization 


\section{PENDAHULUAN}

Keberagaman budaya yang ada di Indonesia merupakan pengakuan terhadap prulalisme budaya yang perlu dipelihara sebagai khasanah kekayaan kebudayaan Indonesia. Dengan adanya pengakuan terhadap perbedaan budaya itu, maka sebagai masyarakat Indonesia harus dapat hidup harmonis dan toleransi kepada sesama. Sikap ini sudah ada sejak nenek moyang bangsa Indonesia salah satunya pada jaman kerajaan Majapahit yang dapat menyatukan Nusantara dengan berbagai latar budaya, agama dan bahasa yang berbeda. Globalisasi yang terjadi di Indonesia saat ini menuntut adanya penguasaan terhadap suatu bidang tertentu ataupun diberbagai bidang. Dalam kehidupan masyarakat modern sekarang ini profesi merupakan suatu bentuk spesialisasi dan spesifikasi pekerjaan yang menuntut kemampuan yang dapat selalu berkembang. Termasuk dalam profesi itu adalah penyedia jasa transportasi seperti angkutan umum, becak dan delman yang selama ini hanya dipandang sebelah mata di daerah Kota Tegal dan sekitarnya.

Di pertengahan tahun 2017 moda transportasi online masuk ke wilayah Kota Tegal dan sekitarnya. Hal ini wajar karena pengaruh globalisasi sudah muncul sepuluh tahun yang lalu di kota besar di Indonesia semakin terasa dalam kehidupan bermasyarakat. Berbagai aspek kehidupan yang ditandai dengan perubahan ekonomi yang sangat signifikan berpengaruh pada aspek-aspek kehidupan lain. Tidak terkecuali dalam budaya menggunakan transportasi yang tidak lepas dari pengaruh globalisasi. Menurut Tilaar (2009: 1) "perubahan global yang sedang terjadi, telah merupakan suatu revolusi global (globalisasi) yang melahirkan suatu gaya hidup (a new life style)". Karakteristik gaya hidup masyarakat global adalah kehidupan yang dilandasi penuh persaingan sehingga menuntut peran individu untuk dapat membenahi diri mengikuti perubahan secara cepat yang terjadi. Perubahan-perubahan global tersebut memberikan tekanan kepada setiap orang dan masing-masing orang memiliki kemampuan pertahanan diri yang berbeda.

Zahid (2015) menjelaskan bahwa "Globalization has not only opened informational exchange from developed to developing countries but has also led to the career prospects across the borders. Now, the individuals are expected to develop skills and competencies so that they can attain better job opportunities and consequently they enter into inter-regional competition." Dengan keterampilan dan kompetensi yang dikuasai dengan baik oleh masyarakat dapat menyokong kehidupannya di masa yang akan datang. Masyarakat di era 'jaman now' ini sangat dimudahkan dengan adanya aplikasi yang terdapat dalam perangkat gawai yang dimiliki dari kalangan tua sampai muda bahkan ekonomi bawah 
sampai atas. Perubahan yang sangat terlihat ditandai dengan kepemilikan smartphone yang tidak mengenal batas usia maupun dari segi ekonomi di Kota Tegal.

Namun adanya berbagai pro dan kontra adanya transportasi online merambah pada masyarakat luas. Dalam berita dilaman news.detik.com "Ratusan awak angkutan di Kota Tegal, Jawa Tengah menggelar aksi demo memprotes beroperasinya layanan transportasi online. Beroperasinya transportasi online ini menurut mereka telah mengurangi pendapatan angkutan konvensional". Adanya reaksi dari masyarakat ini karena adanya perubahan pola penumpang transportasi konvensional beralih ke transportasi online. Finansial yang menjadi inti dari banyaknya penyedia jasa transportasi konvensional menyuarakan pendapatnya. Aliansi Transportasi Tegal yang terdiri dari awak angkutan kota jurusan Tegal-Banjaran, Tegal-Slawi dan ojek di sejumlah pangkalan dan para tukang becak yang masih belum dapat menerima kehadiran pertumbuhan jasa yang berbasis online. Hal tersebut berarti bahwa pemahaman adanya budaya yang masuk belum dapat dipahami secara utuh. Kemauan dan kemampuan diri sangat menentukan tingkat pemahaman tentang budaya baru tersebut.

Di dalam dinamika kelompok yang tejadi sejak adanya fenomena aplikasi berbasis online ada empat hal. Dalam Seokanto (2014) menjelaskan adanya empat hipotesis adanya antagonisme antar kelompok yaitu “(1) bila dua kelompok bersaing, maka akan timbul stereotip, (2) kontak antara kedua kelompok yang bermusuhan tidak akan mengurangi sikap tindak bermusuhan tersebut, (3) tujuan yang harus dicapai dengan kerja sama akan dapat menetralkan sikap tindak bermusuhan, dan (4) di dalam kerja sama mencapai tujuan, stereotip yang semula negatif menjadi positif". Maka perlu adanya pendidikan di masyarakat untuk dapat mengubah stereotip negatif menjadi positif dan saling mendukung. Pendidikan ini khususnya ada dalam konseling lintas budaya yang mempelajari perlilaku manusia dalam sudut pandang konseling yang memahami adanya aspek budaya.

Pendidikan sebagai landasan manusia dalam berperilaku merupakan hal sangat mendasar yang wajib dimiliki oleh setiap individu. Pendidikan tidak hanya pada ranah formal saja, melainkan dalam long life education individu tidak ada batasan untuk belajar. Dalam UU Nomor 20 tahun 2003 Sisdiknas Bab I Ketentuan Umum Pasal 1 Nomor 1 menyatakan bahwa "Pendidikan adalah usaha sadar dan terencana untuk mewujudkan suasana belajar dan proses pembelajaran agar peserta didik secara aktif mengembangkan potensi dirinya untuk memiliki kekuatan spiritual keagamaan, pengendalian diri, kepribadian, kecerdasan, akhlak mulia, serta keterampilan yang diperlukan dirinya, masyarakat, bangsa dan 
negara". Dalam penjelasan pasal tersebut merujuk pada aktualisasi peserta didik dengan segenap potensi yang dimilikinya untuk dapat bersaing di dunia luar nantinya. Pendidikan di masyarakat dilakukan untuk mengedukasi bahwa budaya yang masuk dalam masyarakat tidak serta merta diterima langsung. Namun perlu pemahaman yang baik agar semua pihak mampu menerima budaya yang baru tersebut tanpa adanya konflik yang terlalu tajam.

Nilai-nilai ini yang perlu ada pada diri masing-masing individu. Kompetensi diri untuk dapat survive pada kehidupan global seperti yang dituliskan pada Cornish (2010: 5) “Competency is 'generally understood to mean that a preofessional is qualified, capable and able to understand and do things in an appropriate and effective manner' (Rodolfa et al., 2005, p. 348)". Menjelaskan kompetensi yang dimiliki seseorang yaitu memahami. Arti memahami tidak hanya melihat dari sudut pandang yang satu, namun dapat memahami dari sudut pandang orang lain. Kompetensi sebagai konselor pun harus pada pemahaman pada aspek budaya yang mendominasi masyarakat sehingga menimbulkan berbagai macam perilaku.

Covey (2015:34) “Beberapa dari tulisan ini mengakui karakter sebagai bahan baku kesuksesan, tapi cenderung mengkotak-kotakannya, dan bukan mengakuinya sebagai landasan dan katalis". Bahwa sudut pandang kita cenderung pada kulit luarnya saja, belum masuk pada hakekat sebenarnya dari setiap hal. Sudut pandang masyarakat perlu dilandasi pemahaman yang kuat akan adanya perbedaan budaya. Pemahaman konseling lintas budaya menjembatani antara apa yang terjadi di masyarakat dengan keilmuan sebagai konselor.

\section{METODE PENELITIAN}

Penelitian ini dilakukan menggunakan metode kualitatif. Menurut Mertens (2010: 225) this means that qualitative researchers study things in their natural settings, attempting to make sense of, or to interpret, phenomena in terms of the meanings people bring to them. Penelitian kualitatif dilakukan untuk mengungkap data secara mendalam pada fenomena yang sedang marak terjadi di masyarakat. Jenis penelitian kualitatif yang digunakan adalah fenomenologis yang menurut Mertens (2010: 235) the key characteristic of phenomenology is the study of the way in which members of a group or community themselves interpret the world and life around them. The researcher does not make assumptions about an objective reality that exists apart from the individual. Rather, the focus is on understanding how 
individuals create and understand their own life spaces.

Pendalaman fenomena dilakukan pada responden yang dipilih dari masyarakat Kota Tegal berdasarkan (1) pengguna layanan transportasi aplikasi berbasis online, (2) penyedia jasa transportasi aplikasi online dan (3) penyedia jasa transportasi konvensional. Data yang telah terkumpul kemudian dianalisis menggunakan FGD/ diskusi kelompok untuk mendapatkan hasil data yang komprehensif. Diskusi kelompok dilakukan untuk menganalisis data yang telah dikumpukan dari responden.

\section{HASIL DAN PEMBAHASAN}

\section{Sosial Media dalam Budaya Masyarakat}

Tantangan era globalisasi ini memiliki dampak positif dan negatif. Dampak positif dapat dirasakan dengan adanya berbagai fasilitas teknologi dan komunikasi yang sangat memudahkan manusia. Namun begitu pula dengan dampak negatif yang memiliki pengaruh yang sangat besar. Maka dari itu, untuk dapat membekali manusia Indonesia menghadapi tantangan global perlu adanya suatu pendidikan dalam masyarakat untuk sadar budaya luhur bangsa yang menjadi pilar kehidupan. Dalam UU Nomor 20 Tahun 2003 tentang Sisdiknas menerangkan bahwa pendidikan nasional berfungsi mengembangkan kemampuan dan membentuk watak serta peradaban bangsa yang bermartabat dalam rangka mencerdaskan kehidupan bangsa, bertujuan untuk berkembangnya potensi peserta didik agar menjadi manusia yang beriman dan bertakwa kepada Tuhan Yang Maha Esa, berakhlak mulia, sehat, berilmu, cakap, kreatif, mandiri, dan menjadi warga negara yang demokratis serta bertanggung jawab. Dengan penjelasan tersebut diharapkan manusia Indonesia memiliki sikap demokratis menghargai perbedaan dan keberagaman budaya yang ada di Indonesia.

Saloua (2015) menjelaskan "Students also seem to us little incentive to invest in learning their future profession. They say find difficult asses sments and claim lack of time to prepare the required work." Maka dari itu sangat perlu pendidikan di masyarakat bahwa semua hal yang diadaptasi dari luar perlu disaring dan dipahami bersama. Terutama fenomena adanya banyaknya transportasi online yang sekarang ini menimbulkan pro dan kontra tanpa dipahami oleh masyarakat. Maka masyarakat perlu dipersiapkan untuk menghadapi tiga tugas kehidupan, yaitu (Buchori, 2001: 50) yaitu “(1) Untuk dapat hidup (to make a living), (2) Untuk mengembangkan kehidupan yang bermakna (to lead a meaningful life) dan (3) Untuk turut memuliakan kehidupan (to ennoble life)". Dengan adanya bekal tiga tugas kehidupan bagi masyarakat untuk memasuki dunia global, maka diri individu mampu membekali diri dengan nilai-nilai hakiki kehidupan untuk terus mampu bertahan di situasi globalisasi. Pendidikan di 
masyarakt tidak hanya pembekalan materimateri saja, namun yang lebih penting adalah pembekalan nilai-nilai kehidupan bagi peserta didik. Bagaimana individu memaknai hidup sekarang dan berusaha untuk membekali di kehidupan yang akan datang nantinya.

Memaknai adanya kehidupan dengan perkembangan teknologi sekarang ini merupakan pembelajaran setiap hari di setiap masyarakat. Pineida (2011) menjelaskan "A learning competency is a human ability that facilitates learning. Every habit or ability that helps a student learn more and better is within the learning competency". Setiap kebiasaan akan membantu diri untuk lebih baik untuk dapat belajar menerima hal-hal baru. Adanya perkembangan teknologi sangat bermanfaat bagi kehidupan. Sehingga penggunaannya jangan sampai memberikan efek negatif bagi diri maupun bagi bangsa.

\section{Pengguna Aplikasi Berbasis Online}

Dari data yang telah dikumpulkan pada masyarakat Kota Tegal dan sekitarnya yang menggunakan aplikasi berbasis online sangat beragam. Berdasarkan data wawancara dan obeservasi yang dilakukan selama kurun waktu enam bulan dari bulan Juli - Desember 2017 pada responden yang dipilih dengan dasar penggunaan aplikasi online maka ditemukan data sebagai berukut.

Tabel 1. Data indikator pengguna transportasi online

\begin{tabular}{|c|c|c|}
\hline Indikator & Konvensional & Online \\
\hline Cara mengakses & $\begin{array}{l}\text { Manual dengan datang menuju } \\
\text { tempat tersedianya }\end{array}$ & $\begin{array}{l}\text { Langsung dapat diakses } \\
\text { melalui gawai }\end{array}$ \\
\hline Pilihan moda transportasi & $\begin{array}{l}\text { Becak, delman, angkutan } \\
\text { umum }\end{array}$ & Sepeda motor, mobil \\
\hline Kemudahan & Rute sudah tersedia & $\begin{array}{l}\text { Sampai pada wilayah } \\
\text { pedesaan dan wilayah yang } \\
\text { jauh }\end{array}$ \\
\hline Harga & $\begin{array}{l}\text { Angkutan umum mulai Rp } \\
2.000,00-\mathrm{Rp} 10.000,00 \\
\text { Delman mulai Rp } 2.000,00- \\
\text { Rp } 15.000,00 \\
\text { Becak mulai Rp } 5.000,00-\mathrm{Rp} \\
20.000,00 \\
\text { (Jarak wilayah dekat kecuali } \\
\text { ankutan umum) }\end{array}$ & $\begin{array}{l}\mathrm{Rp} 3.000,00-\mathrm{Rp} \\
23.000,00 \text { (sepeda motor) } \\
\mathrm{Rp} 10.000,00-\mathrm{Rp} \\
69.000,00 \text { (mobil) } \\
\text { Dalam wilayah kilometer } \\
\text { tertentu }\end{array}$ \\
\hline Keamanan & $\begin{array}{l}\text { Sesuai standar kendaraan } \\
\text { umum }\end{array}$ & $\begin{array}{l}\text { Sesuai standar keamanan di } \\
\text { jalan raya } \\
\text { Helm (sepeda motor) } \\
\text { Sabuk pengaman (mobil) }\end{array}$ \\
\hline
\end{tabular}

Adanya transportasi berbasis online yang didapat diakses siapa saja melalui gawainya sangat memberikan kemudahan bagi penggunanya. Tandera et all (2017) "Social media has become the most widely used communication and interaction tool 
between people over the past few years. Direct interaction between people is decreasing as people tend to communicate indirectly through smartphones". Interaksi yang terjadi antara pengguna dan penyedia jasa dapat berlangsung mudah dan cepat. Sehingga pengguna merasakan adanya dampak yang baik bagi kehidupannya seperti efisiensi waktu, tenaga dan uang.

Perubahan budaya begitu nampak signifikan terjadi. Adanya perubahan dari budaya menggunakan transportasi konvensional menjadi berbasis online. Masyarakat yang pada umumnya menggunakan angkutan umum untuk menuju daerah yang jauh maupun dekat sekarang beralih menggunakan transportasi online. Perubahan yang terjadi atas dasar pengetahuan masyarakat dalam menggunakan gawai perlu diapresiasi. Keuntungan bagi pengguna lebih kepada akses yang dapat ditempuh untuk pergi ke sekolah, pusat perbelanjaan, berobat, membeli makanan, dan lain-lain dalam waktu yang cepat dan tidak repot untuk menuju ke pangkalan angkutan umum.

\section{Pengaruh bagi Penyedia Jasa Transportasi Online}

Masyarakat yang menjadi penyedia jasa transportasi online yang menjadi responden terdiri dari penduduk asli yang berdomisili di Kota Tegal dan sekitarnya maupun warga yang berdomisili di luar daerah. Hal yang sangat unik ditemukan pada proses observasi yaitu tidak semua penyedia jasa transportasi online adalah penduduk asli. Banyaknya warga luar daerah yang masuk seperti dari Jawa Timur dan Jawa Barat yang menjadi penyedia jasa transportasi online. Hal ini memberikan indikasi bahwa jenis pekerjaan ini menurut masyarakat memiliki daya tarik yang luar biasa yang sangat menjanjikan dan memiliki pendapatan yang besar. Adanya arus migrasi dari daerah lain menuju ke Kota Tegal tersebut sangat berpengaruh terhadap kebudayaan setempat.

Penyedia jasa transportasi online sebetulnya juga memiliki pekerjaan tetap dalam profesi tertentu. Namun menurut keterangan responden, pendapatan yang diperoleh selama ini belum dapat memenuhi kebutuhan hidup yang semakin hari semakin berat. Pekerjaan yang dilakukan sebelumnya dari para penyedia jasa transportasi online beragam. Ada yang bekerja sebagai pengendara kendaraan umum, pedagang, pengajar, pegawai pabrik, mahasiswa bahkan siswa yang sedang sekolah. Perubahan yang cukup signifkan dilihat dari nilai uang dalam pemenuhan hidup seharihari. Dengan biaya yang tidak sedikit masyarakat berusaha untuk dapat survive di tengah arus globalisasi. Segala cara diupayakan untuk dapat mendapatkan penghasilan yang dapat menutup atau bahkan dapat melebihi dari kebutuhan hidupnya. 


\section{Pengaruh bagi Penyedia Jasa Transportasi Konvensional}

Lain halnya dengan bagi masyarakat penyedia jasa transportasi konvensional sangat sulit awalnya untuk dapat menerima perubahan yang cukup signifikan. Adanya berbagai aksi protes yang ditujukan kepada pemimpin daerah untuk memberikan regulasi yang berimbang kepada jasa transportasi online sangat ditunggu oleh penyedia jasa transportasi konvensional. Perlu adanya sosialisasi bahwa jasa transportasi dapat dilakukan melalui media online. Sehingga masyarakat dapat memahami dan menerima keberadaan jasa era milenial tersebut.

Berdasarkan data observasi dan wawancara yang dilakukan dapat dijelaskan beberapa hal. Angkutan umum, becak dan delman menjadi moda transportasi yang sudah ada digunakan oleh masyarakat. Para penyedia jasa ini mayoritas adalah laki-laki di atas umur 40 tahun. Sangat disayangkan bahwa para generasi muda tidak ikut terlibat dalam pewarisan budaya dalam moda transportasi tradisional yang semakin sedikit ini. Bahkan ada beberapa penyedia jasa berupa becak yang sudah berusia lanjut yang masih aktif bekerja. Hal yang sangat menarik bahwa pekerjaan yang membutuhkan tenaga yang besar dan kuat dilakukan oleh orang-orang yang pada periode perkembangannya sudah diusia lanjut yang seharusnya tidak melakukan aktivitas berat yang memerlukan banyak porsi tenaga.

Kondisi yang sama pula bahkan sangat berubah pada pola penggunaan jasa transportasi konvensional seperti pada becak. Pengguna becak sebagian besar beralih dan dampaknya sangat dirasakan oleh penyedia transportasi ini. Pergeseran budaya menggunakan transportasi becak sangat berpengaruh pada penyerapan tenaga kerja. Usia muda yang produktif dan memiliki tenaga yang besar lebih memilih menjadi penyedia transportasi online.

\section{PEMBAHASAN}

Keberagaman budaya yang ada di Indonesia merupakan pengakuan terhadap prulalisme budaya yang perlu dipelihara sebagai khasanah kekayaan kebudayaan Indonesia. Dengan adanya pengakuan terhadap perbedaan budaya itu, maka sebagai masyarakat Indonesia harus dapat hidup harmonis dan toleransi kepada sesama. Dengan kesadaran akan adanya keberagaman budaya, maka individu perlu belajar baik dalam lingkup pendidikan maupun pada masyarakat. Pemecahan masalah, pemahaman dan kesadaran akan keberagaman budaya membawa pada kemampuan beradaptasi, menerima perbedaan, membangun hubungan yang luas, mengatasi konflik yang berakar pada perbedaan budaya dan memenangkan globalisasi. 
Dengan adanya konseling lintas budaya maka dapat memahami masyarakat pada perbedaan yang ada. Diharapkan dengan adanya pemahaman multikultural akan berdampak pada keharmonisan hidup bersama. Tidak ada lagi kasus SARA, berbagai aksi protes dan pelanggaran hakhak asasi manusia lagi. Karena sudah ada kesadaran diri bahwa manusia adalah makhluk sosial. Pendidikan di masyarakat merupakan usaha sadar untuk mentransformasikan nilai-nilai landasan filsafat pendidikan. Namun pendidikan tidak hanya pemberian materi pelajaran kepada peserta didik, namun yang lebih penting adalah penanaman nilai-nilai dasar hakiki yang memiliki kebenaran sejati yang tidak tersekat ruang dan waktu. Nilai-nilai walau berbeda materi tapi memiliki nilai yang sama. Bentuk dari nilai-nilai tersebut antara lain cinta, kejujuran, keadilan, ketuhanan, kerukunan, kesejahteraan, kemanusiaan, kecerdasan yang kesemuanya menjadi arah, pegangan dan pedoman hidup manusia.

Dengan adanya konseling lintas budaya maka penanaman nilai-nilai tersebut kepada masyarakat akan membawa masyarakat untuk mampu beradaptasi dan memegang teguh nilai-nilai pada dirinya saat bersaing di dunia global. Dibutuhkan juga suatu sistem pendidikan nasional yang bersifat dinamis dan fleksibel terhadap perkembangan teknologi dan komunikasi yang didasarkan pada sikap demokratis dan menghargai sesama manusia. Jadi dalam globalisasi tetap manusia itu bersaing namun tidak terlepas dari sikap toleransi dan menghargai sesama. Karena pada dasarnya manusia adalah makhluk sosial yang tidak dapat hidup tanpa adanya bantuan dari orang lain.

Globalisasi membuat para anak bangsa terbuai dan dimanjakan dalam berbagai perangkat komunikasi dan teknologi. Namun berbagai media tersebut malah menjadi ancaman dampak negatif bagi generasi muda. Berbagai tindakan negatif efek dari efek globaliasi berupa multimedia yang sangat mudah diakses namun berujung pada lunturnya rasa cinta tanah air seperti perilaku dengan bangga menggunakan produk luar negeri, perilaku pornografi dan pornoaksi yang dilakukan masyarakat, kekerasan atau aksi berujung anarkis di masyarakat, gaya hidup hedonis konsumtif, pemborosan energi (listrik, bahan bakar fosil dan bahan bakar minyak) dan gaya hidup bebas yang berujung pada degradasi moral.

Maka setidaknya masyarakat dapat menyikapi perubahan dalam menggunakan gawai dengan beragam aplikasi berbasis online dengan bijak. Hal-hal yang dapat dilestarikan sebagai budaya ketimuran jangan sampai tergerus dengan adanya adaptasi yang bebas diterapkan di masyarakat. Kehidupan sejatinya memerlukan kerja keras untuk dapat mensejahetakan masyarakat dalam konteks material maupun sejahtera yang hakiki. Hal 
yang sangat baik ini perlu diwariskan dari generasi ke generasi.

\section{KESIMPULAN DAN SARAN}

Dapat disimpulkan bahwa masyarakat di Kota Tegal sangat terbuka terhadap perubahan, dapat beradaptasi dengan globalisasi dan menjadi masyarakat yang sadar akan kebutuhan teknologi. Pengguna jasa transportasi sangat terbuka terhadap perubahan khususnya dalam perkembangan teknologi. Perlu adanya informasi dan regulasi yang berimbang pada penyedia jasa transportasi berbasis online maupun konvensional. Tidak lepas adanya pemahaman lintas budaya pada masyarakat untuk dapat menyikapi perubahan yang terjadi. Sehingga nilai-nilai masyarakat yang membangun bangsa tidak tergerus dan hilang ditelan maraknya arus globalisasi yang membawa budaya-budaya baru. Kepekaan diri terhadap lingkungan sosial pun tidak hilang walau dengan adanya gawai yang setiap saat digunakan dalam berinteraksi pada masyarakat.

\section{DAFTAR PUSTAKA}

Buchori, Mochtar. 2001. Pendidikan Antisipatoris. Yogyakarta: Kanisius.

Cornish, Jennifer A. Ericson et all. 2010. Handbook of Multicultural Counseling Competencies. New Jersey: John Wiley \& Sons, Inc.

Covey, Stephen R. 2015. The Seven Habits of Highly Effevtive People (7 Kebiasaan Manusia yang Sangat Efektif). Jakarta: PT Dunamis Intra Sarana.

Pineida, Felipe Oyarzo. (2011). Competencies for the 21st Century: Integrating ICT to Life, School and Economical Development. Procedia - Social and Behavioral Sciences. (28): $54-57$.

Mertens, Donna M. 2010. Research and Evaluation in Education and Psychology: integrating diversity with quantitative, qualitative and mixed methods $3^{\text {th }}$ Edition. Sage Publication Inc: United States of America.

Ratusan Awak Angkot Tegal Demo Tolak Transportasi Online. Imam Suripto. Senin 11 September 2017, 11:47 WIB. https://news.detik.com/jawatengah/3637305 /ratusan-awak-angkot-tegal-demo-tolaktransportasi-online diakses pada [10102017]

Saloua, Bani. (2015). Improve student success through their realities. Procedia - Social and Behavioral Sciences. (174): 383 - 389.

Soekanto, Soerjono dan Budi Sulistyiwati. 2014. Sosiologi Suatu Pengantar. Jakarta: Rajawali Pers.

Tandera, Tommy et all. (2017). Personality Prediction System from Facebook Users Personality Prediction System from Facebook Users. Procedia - Social and Behavioral Sciences. (116): $604-611$.

Tilaar, H.A.R. 2009. Membenahi Pendidikan Nasional. Jakarta: Rineka Cipta.

Undang-undang Nomor 20 Tahun 2003 tentang Sistem Pendidikan Nasional

Zahid, Gulnaz. (2015). Globalization, nationalization and rationalization. Procedia - Social and Behavioral Sciences. (174): $109-114$. 